\title{
Experiences Faced by Diabetic Teenagers of Diepkloof Soweto: A Systematic Review
}

\author{
Mahlodi Malatji1*, Thobeka Nkomo ${ }^{1}$
}

${ }^{1}$ University of Witwatersrand, South Africa

*Corresponding Author: mahlodzi@gmail.com

Citation: Malatji, M. and Nkomo, T. (2017). Experiences Faced by Diabetic Teenagers of Diepkloof Soweto: A Systematic Review. Pedagogical Research, 2(1), 02.

doi: $10.20897 /$ pedre. 201702

Published: June 15, 2017

\section{ABSTRACT}

\begin{abstract}
Background: Diabetes is a metabolic disorder which presents itself with symptoms such as blurry vision, thirst and weight loss. It is a disease that is more common in childhood whereby the body cannot produce enough insulin.
\end{abstract}

Objectives: To explore the challenges experienced by diabetic teenagers.

Results: Checking of sugar levels and injecting of insulin was indicated as one of the major difficulties the teenagers face. Findings demonstrated that they feel abnormal and not part of their peers when they have to check their insulin and inject frequently.

Methods: Various literatures from electronic database and manuals were used. The literature review was followed by in-depth semi structured interviews to document the experiences of the diabetic teenagers.

Conclusion: Findings demonstrated challenges encountered by diabetic teenagers which affected their adherence to treatment. Some of the challenges were injecting insulin into their body system and further checking the level of sugar in the blood stream. Some teenagers also reported the dislike to gaining weight as they omit insulin intake in order to conform to a certain body shape. Empower the teenagers in regard to embracing their condition so that they can adhere successfully to the treatment without any relapse in order to avoid readmissions at the hospital.

Keywords: relapse, empowerment, peer pressure, diabetic teenagers

\section{INTRODUCTION}

Living with diabetes is perhaps the most challenging for adolescents. This is because the diabetic condition requires the person to adhere to a certain kind of behaviour guided by the medical practitioners. The aim of the paper is to explain challenges faced by diabetic adolescents of Diepkloof, Soweto, South Africa. The paper will first discuss diabetes as a metabolic disorder. It will then focus on literature review with a particular emphasis on teenagers in Diepkloof, then the methodology applied and findings.

According to Society of Endocrinology, Metabolism, and Diabetes South Africa (2012), Diabetes mellitus (diabetes) is a metabolic disorder with heterogeneous aetiologies that is characterised by chronic hyperglycaemia and disturbances of carbohydrate, fat, and protein metabolism resulting from defects in insulin secretion, insulin action or both. The disorder leads to a high or low level of glucose in the blood system which might lead to premature death if not controlled. South Africa is faced with the intense growth of diabetes and if not treated, it will leave family members without their loved ones. Recent data indicated that, in 2010, the prevalence of type 2 
diabetes in South Africa was estimated at $4.5 \%$ (www.stasticssa.2015). After analysing the statics of the number of positively tested diabetic people in South Africa, it has become more important for people to conduct regular diabetes tests. Early discovery can lead to early treatment and save lives. Researchers like Scanner, Falck; Keskitalo \& Hautala (2016) contends that diabetes is an enduring disease affecting both the daily life and, potentially, the future health of teenagers. This is because teenagers who are diabetic face major responsibilities to adhere to treatment and avoid relapse.

Notwithstanding the above, it is still a challenge for diabetic teenagers to fit in society, as a result of stigmatization and lack of education and understanding about the disease. Teenagers in Diepkloof Soweto with diabetes endure all aspects of the social diabetes-related stigma; in their belief they were just deprived of a normal life. As a result teenagers are regards to be in the sixth stage of Erik Erikson stage of psychosocial development which is intimacy versus isolation. The teenagers felt that they were deprived of a normal life as they were constantly reminded of taking their treatment, following a specific eating plan and have limited participation in sports.

Society finds it hard to accept and support teenagers with such a chronic disease as they feel that having diabetes or any other chronic disease is a curse. According to McDowell \& Newell (1996, p. 125) Social Support is 'the availability of people whom the individual trusts, can rely on, and who make the individual feel cared for and valued as a person', However diabetic teenagers experience lack of such social support. The society finds it difficult to understand the severity of the illness and also unable to show support to the teenagers who are diabetic.

The society finds it difficult to understand the severity of the illness and this may result in some of them unable to show support to the diabetic teenagers. As a result parents and the society need to be educated on diabetes. Such education will enable individuals to embrace the diseases and also be able to comprehend on measures that need to be taken once one is diagnosed with diabetes. Furthermore it will also provide them with knowledge of the disease affects one's socio-economic life and will also assist families on how insulin is injected/administered into one's body. In regards to the light shed above on literature and research conducted in various studies, this paper discusses some of the major challenges faced by diabetic teenagers who resides in Diepkloof Soweto in their daily lives, the paper also addresses socialization of diabetic teenagers into everyday normal life circumstances.

\section{BACKGROUND}

Diabetes is a metabolic disorder which mostly affects or presents itself with symptoms such as blurry vision, constant thirst, unexplained weight loss and wounds which are not easy to heal. There are two types of diabetes namely diabetes mellitus type 1 and type 2 but this paper only focuses on type 1 as it is the one that is mostly affects adolescents or teenagers.

Type 1diabetes is one of the most common chronic diseases of childhood, with a peak age of onset during adolescence. Diabetes presents itself with various symptoms such as thirst, blurry vision, polyuria and weight loss (SEMDSA, 2012). Thus individuals suffering from diabetes are also prone to other diseases such as, cardiac diseases. Cardiac disease is defined as the abnormal functioning of the heart or blood vessels supplying the heart with the nutrients and regulates blood flow.

(Global Clinical Trials Review, 2013). Type 1 diabetes in children can be described as a disease where the pancreas no longer produces enough Insulin to sustain the child, which can be fatal and lead to premature death. Serlachius, Northam, Frydenberg \& Cameron (2011) argues that adolescents with type 1 diabetes mellitus (T1DM) face a major dual challenge of having to manage a chronic health illness as well as the developmental tasks of being an adolescent. Adolescent stage presents with hormonal changes and bodily changes which can affect the blood sugar levels in someone with diabetes. Whenever the blood sugar levels drops, the individual with T1DM can be rendered unconscious. According to Chothia (2013: p2), "Teenagers with diabetes are more sensitive and are less adventurous as they are concerned about how certain activities could affect their blood sugar levels".

It becomes a huge task for teenagers with such chronic diseases to basically manage being in a transitioning puberty stage and also having to manage diabetes. According to Erik Erikson eight stages of development, teenagers are faced with identity and role confusion which can result in them been unable to balance or normalise the environment they live in and also adhere to treatment. According to South African journal $(2014,57)$ "patients inevitably respond differently to the diagnostic news, some may experience shock which may cause emotional distress while others may respond indifferently or with relief as the reason for symptom presentation can now be explained". The diagnostic news comes as a shock to the diabetic teenagers which results in mixed emotions. Researchers argue that adolescents with type 1 Diabetes Mellitus are considered to be a vulnerable population due to the deterioration in glycaemic control and the increased risk for life-threatening diabetes-related complications (Bryden et al., 2001; Sochett and Daneman, 1999). 


\section{PROBLEM STATEMENT}

As demonstrated on above, it clearly indicates the difficulties teenagers face because they are still at a transition stage moving from childhood to adulthood. Thus makes it hard for them to carry all the responsibilities of administering to the adherence of treatment. Petroy (2008) states that, "children and adolescents face various psychosocial barriers to effective diabetes management". Such barriers include denial, embarrassment, anger, resentment, isolation, anxiety, guilt, and depression (Petroy, 2008). Hence due to psychological barriers teenagers tend to relapse in taking their medication as required. "As with any chronic disease, the psychosocial barriers come in depressive fashion and bring unique challenges at each developmental stage", (Petroy, 2008). According to Donald, Dower, Ware, Mukandi, Parekh \& Bain (2012), Diabetes mellitus is a major global public health threat. The psychological and social impact of diabetes on individuals with the disease can be severe, and if not effectively addressed, can lead to the worsening of the overall disease picture. Therefore the summary and synthesis of the paper will basically explore the challenges faced by diabetic teenagers on a daily basis concerning the treatment, the difficulties in adhering to treatment and also assist in implementing strategies that will help the diabetic teenagers and their families cope with diabetic. . Furthermore it will also assist in educating the diabetic practitioners to comprehend the challenges faced by the diabetic teenagers. Thus the practitioners can not only deal with the disease but also with the psychological being of the patient.

Anthi, Asonitou \& Koutsouki, (2011) states that, school absenteeism for diabetic learners cannot be predicted. Thus it is common that learners with diabetes are frequently absent from school due to regular sickness and frequent admission at hospitals. The interpretation of school absences is not easy, but diabetic learners have to face this abnormal situation as a fact and not feel guilty or insecure. Hence at times when the learners have not yet disclosed that they are diabetic and are absent from school, As a result most learners suffer from school phobia also known as school refusal stated by Le Heuzey (2008). According Anthi, Asonitou \& Koutsouki, (2011) school phobia is the phenomenon characterized by a multipart and extreme form of anxiety about going to school. Ohki, Kishi, Orimo, \& Ohkawa, (2004), cited in (Anthi, Asonitou \& Koutsouki, (2011) states that, lack of socialization at school or rejection by fellow learner's results in learners suffering from school phobia. Anthi, Asonitou \& Koutsouki, (2011) argues that teachers are also responsible for informing and promoting harmonic co-existence of non-diabetic and diabetic learners and ensure good relationships among learners (Nakamura, Kanematsu, Yokota, Takedi, Numura \& Maru, 1997). Parents in the context of school life should interact with educators on a regular basis and support their child in achieving a productive, pleasant and safe school life (Anthi, Asonitou \& Koutsouki, (2011).

According to the South African Schools Act No 84 of 1997, S (5) (a) which states that: If a learner who is subject to compulsory attendance in terms of subsection (1) is not enrolled at or fails to attend a school, the Head of Department may investigate the circumstances of the learner's absence from school. As a result neither the teacher nor the head master should take the initiative to investigate the learner's absenteeism from school. This could be done through getting hold of learner's parents or even asking the learner's friends at school to basically get know the whereabouts of the learner.

South African Schools Act No 84 of 1997: subsection (1) states that, "every parent must cause every learner for whom he or she is responsible to attend a school". As a result it is the parent's role to let the teachers know if the child will be absent from school as well.

\section{RESEARCH METHOD AND DESIGN}

The study utilised the qualitative research, which involved the participant's beliefs and values. The study also used the explanatory research design (De Vos Strydom, Fouche \& Delport, 2005). The design was aimed at understanding why a series of events occur and how these events take place. Events such as been ill-treated by the society and non-adherence to treatment. Seven participants were used in the study. The participants were teenagers who are diabetic around Soweto Diepkloof. The tool used to collect the data was semi structured interviews which lasted for 45 minutes per interview. Furthermore the data gathered in the study was analysed using the thematic analysis.

\section{Review Question}

Study was structured using PICOT format namely element population of interest (P), intervention (I), comparisons $(\mathrm{C})$ and outcome $(\mathrm{O})$. The study also used the setting $(\mathrm{S})$ identifying where the study was conducted to gather information for the study. 
Table 1. Use of the PICOT Format.

\begin{tabular}{|l|l|}
\hline POPULATION & Diabetic teenagers \\
\hline INTERVENTION & None \\
COMPARISONS & Not applicable \\
\hline OUTCOME & $\begin{array}{l}\text { Negative outcome, as diabetic teenagers finds it hard to embrace the diagnostic } \\
\text { news and also have difficulties in adhering with treatment. This is because they } \\
\text { omit insulin intake to manage their body weight. }\end{array}$ \\
\hline TIME & Not applicable \\
\hline SETTING & Institutional and community setting \\
\hline
\end{tabular}

\section{Gathering and Classifying Evidence}

The following step is to gather literature that is relevant to the study. The search process should be as transparent as possible and predictable in a way that enables it to be evaluated and reproduced (Centre for Reviews and Dissemination 2009:16). A comprehensive search was conducted to ensure inclusion of many studies (Akobeng 2005:847).The following key words was used to gather information: Empowerment, relapse, experiences, peer pressure, diabetic teenagers, insulin, insulin omission and overweight.

\section{Search Strategy}

A systematic search for research is one of the major differences between a traditional literature review and a systematic review (Briggs, 2001). The aim of search strategy is to identify as many studies on the topic of interest as is reasonably possible. The search was done to identify the minimal primary sources utilised and to also elude selection bias.

\section{Selected Study to be Included}

Selection criteria are utilised in assistance of determining which studies should be included in the systematic review. Different studies were selected by means of inclusion and exclusion.

Table 2. Databases of completed and current research.

\begin{tabular}{|l|l|l|}
\hline Databases(Platforms) & Databases & Completed and Current Research \\
\hline \multirow{5}{*}{ EBSCO } & Academic search premier & \\
\cline { 2 - 3 } & PsycINFO & Scholarly articles in Behaviour \\
\cline { 2 - 3 } & Science Direct & $\begin{array}{l}\text { International journals on Healthcare science- } \\
\text { primary studies }\end{array}$ \\
\cline { 2 - 3 } & Med Pub & - \\
\hline & Sage Journals & - \\
\hline \multirow{3}{*}{} & Google scholar & Scholarly literature \\
\cline { 2 - 3 } & $\begin{array}{l}\text { Manual Search: Reference of } \\
\text { Primary }\end{array}$ & All References \\
\hline
\end{tabular}

\section{Inclusion Criteria}

Research studies published journals; published theses However, when possible, non-English language publications are also included in the systematic review, although the logistics of translating multiple research reports increases the complexity and cost of these reviews(Briggs,2001). However in this review only publications with English language were included. Inclusive of well English written abstracts from the English publications making it less costly on reviews.

\section{Exclusion Criteria}

Primary studies before 2000

Primary studies published in foreign language. The studies were omitted because they are not recent and more upgraded data is needed that can relate to the study.

\section{Performing Critical Appraisal}

Critical appraisal aims to discover whether the methods, and results of the research, are valid (Briggs, 2001). The rigour of the research refers to the degree to which the design of the study and its conduct has minimised the risk of bias. 


\section{Findings of Evidence and Summary of the Study}

Summary of the evidence gathered through interviews presents cumulative information. It also gives a thorough explanation of extraction and data synthesis, discussions and making recommendations.

\section{Performing Critical Appraisal}

Selection criteria was utilised in assistance of determining which studies should be included in the systematic review. Different studies were selected by means of inclusion and exclusion.

Table 3. Findings from selected studies in South Africa.

\begin{tabular}{|c|c|c|c|c|}
\hline Studies & Sample & $\begin{array}{l}\text { Research } \\
\text { question }\end{array}$ & Research outcome & Findings \\
\hline \begin{tabular}{|l|} 
Diabetes \\
South Africa \\
$(2015)$
\end{tabular} & $\begin{array}{l}\text { Diabetic } \\
\text { teenagers }\end{array}$ & $\begin{array}{l}\text { What are the } \\
\text { challenges faced } \\
\text { by diabetic } \\
\text { teenagers? }\end{array}$ & $\begin{array}{l}\text { Teenagers may be targeted for } \\
\text { things like having to check their } \\
\text { blood glucose levels, having to give } \\
\text { injections, being on a stricter diet } \\
\text { plan or being called a "druggy" for } \\
\text { using needles. In particular such } \\
\text { responsibilities can be } \\
\text { inconvenient for teens (Diabetes } \\
\text { South Africa, 2015) }\end{array}$ & $\begin{array}{l}\text { Participant indicated that they are } \\
\text { not being bullied by their friends } \\
\text { or peers, however they are the } \\
\text { ones who feel abnormal towards } \\
\text { their friends who are not diabetic. }\end{array}$ \\
\hline $\begin{array}{l}\text { South } \\
\text { African } \\
\text { journal } \\
(2014)\end{array}$ & & $\begin{array}{l}\text { How did the } \\
\text { diabetic } \\
\text { teenagers react } \\
\text { when they were } \\
\text { first diagnosed } \\
\text { with diabetes? }\end{array}$ & $\begin{array}{l}\text { Patients inevitably respond } \\
\text { differently to the diagnostic news, } \\
\text { some may experience shock which } \\
\text { may cause emotional distress while } \\
\text { others may respond indifferently } \\
\text { or with relief as the reason for } \\
\text { symptom presentation can now be } \\
\text { explained(South African Journal, } \\
\text { 2014) }\end{array}$ & $\begin{array}{l}\text { Participants indicated confusion } \\
\text { when the diagnostic news where } \\
\text { broken to them. }\end{array}$ \\
\hline \begin{tabular}{|l|} 
Ambler et al, \\
2010. \\
Country \\
Australia.
\end{tabular} & $\begin{array}{l}\text { Diabetic } \\
\text { girls }\end{array}$ & $\begin{array}{l}\text { How } \\
\text { teenagers } \\
\text { perceive } \\
\text { gain? }\end{array}$ & $\begin{array}{l}\text { Participants prefer being } \\
\text { underweight or rather omit insulin } \\
\text { intake to conform to their } \\
\text { perceived body image }\end{array}$ & $\begin{array}{l}\text { Females are more conscious of } \\
\text { their weight and therefore find it } \\
\text { hard to use their treatment as they } \\
\text { do not want to gain weight } \\
\text { Participants feel abnormal being } \\
\text { overweight and different from } \\
\text { their friends who are not } \\
\text { overweight. }\end{array}$ \\
\hline $\begin{array}{l}\text { Hamiel et al, } \\
\text { 2015.U.S.A }\end{array}$ & $\begin{array}{l}\text { Overweight } \\
\text { teenagers. }\end{array}$ & $\begin{array}{l}\text { What } \\
\text { omission } \\
\text { insulin? }\end{array}$ & $\begin{array}{l}\text { It is always difficult for diabetic } \\
\text { teenagers to inject and also check } \\
\text { their insulin. Media also plays a } \\
\text { major role in displaying the } \\
\text { accepted weight. Therefore } \\
\text { diabetic teenagers prefer to omit } \\
\text { the insulin intake to manage their } \\
\text { weight. }\end{array}$ & $\begin{array}{l}\text { Hamiel \&Levy -Shraga (2015) } \\
\text { argues that, insulin omission is a } \\
\text { unique purging behaviour available } \\
\text { to individuals with type } 1 \text { diabetes } \\
\text { mellitus (T1DM). Participants } \\
\text { omit insulin intake to manage } \\
\text { weight. Leading to lack of proper } \\
\text { treatment management. }\end{array}$ \\
\hline
\end{tabular}

\section{DISCUSSION AND CONCLUSION}

The above section (discussion and conclusion) may lead to recommendations which may be empowering the diabetic teenagers and the society as well. Empowerment of people with diabetes means integrating diabetes with identity. However, others' stigmatization can influence it. Although diabetes is so prevalent among South Africans, there is little knowledge about diabetes-related stigma in South Africa. Likewise, the findings of Weiler (2007) showed that, "others see people with diabetes as sick patients who are unable to do their daily activities and will certainly experience amputation and a sudden death". Thus education of the disease is important. 


\section{REFERENCES}

Akobeng, A.K., (2005). 'Understanding systematic reviews and meta-analysis', Archives of Disease in Childhood 90(8), 845-848.

Ambler, G., Cameroon, F., \& Gillbank. J (2010).Caring for diabetes in cbildren and adolescents. (3rd Ed).Australia. National library of Australia.

Anthi, P., Asonitou, K., \& Koutsouki, D. (2011): Exercise Training in Students with Diabetes. Role of PE Teacher at School.7 (2), 177-184.

De Vos, A.S., Strydom, H., $\quad$ Fouche, C.B., \& Delport, C. (2005). Research at grass roots: For Social Sciences and Human Services Professions. ( $3^{\text {rd }}$ Ed). Pretoria. JL van Schaik.

Hamiel, P., Hamiel, U., \& Shraga, Y. (2015). Eating disorders in adolescents with type 1 diabetes: Challenges in diagnosis and treatment.

Le Heuzey, M. F. (2008). School phobia or school refusal? Rev Prat, 58(7), 741-744.

Nakamura, M., Kanematsu, Y., Yokota, M., Takeda, J., Nakamura, N., \& Maru, M. (1997). Social support of chronically-ill children and healthy children. Nihon Kango Kagakekaishi, 17(1), 40-47.

Weiler, M. (2007). The socio-cultural influences and process of living with diabetes for the migrant Latino adult, in nursing school. USA: The University of Arizona;

www.Diabetes South Africa.com (2015).

www.South African Journal.com (2014).

Statistics South Africa. South Africa. Mid-year population estimates 2015. 2015 (July). Available from: http://www.statssa.gov.za/publications/P0302/P03022015.pdf

www.South African Schools Act No 84 of 1996.com. 